\title{
SENTIDOS DO REFÚGIO EM DOCUMENTOS OFICIAIS: ANÁLISE DISCURSIVA E POLÍTICA LINGUÍSTICA
}

\author{
Meanings of refuge in official documents: \\ Discursive analysis and language policy
}

\author{
Bruno Deusdará ${ }^{1}$ \\ Universidade do Estado do Rio de Janeiro \\ Poliana Coeli Costa Arantes ${ }^{2}$ \\ Universidade do Estado do Rio de Janeiro
}

\section{RESUMO}

No presente artigo, interrogamos os sentidos construídos acerca das práticas de linguagem, em documentos de referência sobre o instituto do refúgio no Brasil. Adotamos, nessas análises, uma perspectiva discursiva, fundamentada nos princípios da interdiscursividade (BAKHTIN, 2011, MAINGUENEAU, 2005) e da prática discursiva (MAINGUENEAU, 1997). Selecionamos, para as análises, o Decreto-Lei de 1960, do Senado Federal, e a Declaração do Brasil, de 2014. Como resultados obtidos, identificamos um apagamento da dimensão linguística vivenciada pelos refugiados, a partir do qual produzimos alguns questionamentos acerca de políticas linguísticas dirigidas a essa população.

Palavras-Chave: Discurso. Refúgio. Prática de linguagem.

\begin{abstract}
In this article, we examine the meanings constructed in language practices regarding refugee status in Brazil. In the analysis, we adopted a discursive approach based on the principles of interdiscursivity (BAKHTIN, 2011, MAINGUENEAU, 2005) and discursive practice (MAINGUENEAU, 1997). We selected the 1960 Decree-Law of from the Federal Senate and the 2014 Brazilian Declaration of. In the analysis, we observed the omission of language policies experienced by the refugees, and hence some questions were raised vis à vis language policies geared towards this population.
\end{abstract}

Keywords: Discourse. Refuge. Language practice.

\section{RESUMÉN}

En el presente artículo, interrogamos los sentidos construidos acerca de las prácticas de lenguaje, en documentos de referencia sobre el instituto del refugio en Brasil. En estos análisis, adoptamos una perspectiva discursiva, fundamentada en los principios de la interdiscursividad (BAKHTIN, 2011, MAINGUENEAU, 2005) y de la práctica discursiva (MAINGUENEAU, 1997). En los análisis, el Decreto-Ley de 1960, del Senado Federal, y la Declaración de Brasil, de 2014. Como resultados obtenidos, identificamos un borrado de la dimensión lingüística vivida por los refugiados, a partir del cual producimos algunos cuestionamientos acerca de políticas lingüísticas dirigidas a esa población.

\footnotetext{
${ }^{1}$ Professor de Linguística da Graduação e dos Programas de Pós-graduação em Letras (ILE) e em Letras e Linguística (FFP) da UERJ. Bolsista dos Programas Prociência (UERJ/FAPERJ) e Jovem Cientista do Nosso Estado (FAPERJ). Doutor em Psicologia Social (UERJ). E-mail: brunodeusdara@ gmail.com O presente trabalho foi realizado com apoio da Coordenação de Aperfeiçoamento de Pessoal de Nível Superior - Brasil (CAPES) - Código de Financiamento 001.

${ }^{2}$ Professora de Língua e Literatura Alemã da Graduação e do Programa de Pós-graduação em Letras (ILE) da UERJ. Bolsista dos Programas Prociência (UERJ/FAPERJ). Doutora em Estudos da Linguagem (UFMG). E-mail: polianacoeli@yahoo.com.br
} 
Palabras clave: Discurso. Refugio Práctica del lenguaje.

Recebido em: janeiro 2019

Aceito em: setembro 2019

DOI: $10.26512 /$ les.v20i2.22049

\section{CONSIDERAÇÕES INICIAIS}

No presente artigo, analisamos os sentidos atribuídos às práticas de linguagem em documentos oficiais sobre o refúgio, buscando compreender o lugar conferido à promoção de política e de práticas de integração visando aos direitos linguísticos e à qualidade das interações verbais desenvolvidas pela população de refugiados no Brasil. A partir desse objetivo, pode-se extrair uma outra discussão, aquela que busca apreender de que modo se constroem, nesses documentos, os desafios e os impasses vividos por essas populações na dinâmica da integração local, assumindo contornos que procurem evidenciar uma problemática relativa às políticas linguísticas, ou à ausência delas, e aos direitos linguísticos dessa população. Com base em nossa inscrição no campo de estudos do refúgio, formulamos a seguinte hipótese de trabalho, que orienta nossa investigação: o lugar conferido às práticas de linguagem encontra-se secundarizado frente ao interesse por regulamentar administrativa e juridicamente a condição de refugiado.

Entre os diversos aspectos que argumentam favoravelmente à inserção de pesquisadores e profissionais oriundos de diferentes campos do saber nas redes de acolhimento a refugiados, destacamos o aumento vertiginoso das solicitações de refúgio entre nós. De acordo com dados da Polícia Federal, as solicitações passaram de 966 a 28.670, entre 2010 e 2015, caracterizando um aumento de 2.686\%. Nos anos de 2016 e 2017, registrou-se uma queda no número de solicitações, que não deixam de permanecer evidenciando a urgência das reflexões e das ações de integração.

A diversidade de origem das pessoas que solicitam refúgio se expressa em 79 nacionalidades. Entre os solicitantes, as populações mais numerosas são de haitianos, senegaleses, sírios, bengaleses, nigerianos. Já entre os refugiados, as populações mais numerosas são compostas por sírios, angolanos, colombianos, libaneses. Apenas por esses dados, ainda que bastante genéricos, do perfil populacional compreendido, já se pode inferir a complexidade do fenômeno do refúgio entre nós e demanda de engajamento interdisciplinar e de diferentes atores sociais nessa rede.

Delineada desse modo, a composição da referida população já anuncia questões que merecem especial atenção, como a configuração de um fluxo de deslocamentos que passa a considerar o Brasil como um dos destinos daqueles grupos que chegam a cruzar as fronteiras nacionais e, em alguns casos, continentais. Registre-se, a esse respeito, que, dos sessenta e sete milhões de pessoas deslocadas no mundo atual, de acordo com dados do ACNUR, mais de quarenta milhões permanecem 
nas fronteiras dos países mais pobres, denunciando problemas de ordem muito mais variada do que aqueles que habitualmente ganham contornos midiáticos entre nós, com focos em travessias dramáticas e trajetórias individuais, especialmente em "tentativas" de ingresso no território europeu.

Assim, ao mesmo tempo em que o fenômeno dos deslocamentos se configura com centralidade na ordem internacional contemporânea, as restrições à mobilidade emergem igualmente como questão a ser enfrentada, na análise dessa problemática. A esse respeito, Paiva, Dias e Moulin ressaltam que a intensificação dos fluxos de deslocamento evidencia, entre outros aspectos,

as transformações dos mecanismos de produção da desigualdade, com o crescimento das restrições à mobilidade, por exemplo, com a explosão de barreiras físicas e legais aos indesejados e sua redução a uma condição de imobilidade, ao mesmo tempo em que se acelera o movimento entre tempos e espaços cada vez mais uniformes para aqueles que participam necessária e ativamente das engrenagens do capitalismo globalizado (PAIVA; DIAS; MOULIN, 2018, p. 9)

Com efeito, essa tensão que se caracteriza pela possibilidade de se deslocar e pelas restrições destaca a "heterogeneidade do acesso ao direito de ir e vir, local e globalmente", que se sobrepõe à "fragmentação dos mecanismos de controle, disciplina e permanência dos e nos possíveis espaços de sobrevivência na conjuntura atual" (PAIVA; DIAS; MOULIN, 2018, p. 9-10). Trata-se, a nosso ver, de um potente vetor de produção de sentidos que atravessa e constitui as narrativas acerca das experiências de refúgio, reiteradamente reenviadas ao contexto de travessia das fronteiras. Um efeito correlato desse reiterado reenvio reside no apagamento das condições de inserção dessas populações em circunstâncias de integração local. Neutralizam-se os desafios cotidianos, compondo-se uma cena discursiva na qual os refugiados são interpelados tão somente pela dinâmica da travessia e se apagando outras dimensões, como destaca Ramos: "el inmigrante se encuentra ubicado en un entorno cultural difícil en el que su cultura identitariapuedesentirse oprimida enalgún sentido, aun de manera inconsciente, por la cultura dominante" (RAMOS, 2016, p. 289). Em referência a leituras de Hannah Arendt, Agamben destaca um paradoxo: "justamente a figura - o refugiado - que deveria ter encarnado por excelência os direitos do homem assinala, pelo contrário, a crise radical desse conceito" (AGAMBEN, 2015, p. 27).

Com base nessa discussão, passamos a caracterizar a perspectiva discursiva que temos praticado, observando especialmente as ferramentas teóricas com as quais temos podido nos inserir nas redes de acolhimento a refugiados, no contexto do Rio de Janeiro. Na sequência, apresentamos uma discussão que contextualiza os documentos a serem submetidos à análise e justifica a opção pela investigação dos referidos documentos. Na discussão dos resultados obtidos por meio das análises, apresentamos questões acerca de uma política linguística com refugiados, ainda silenciada nos documentos de referência. 


\section{A INDISSOCIABILIDADE ENTRE LINGUAGEM E MUNDO}

Neste item, apresentamos os princípios teóricos que organizam nosso modo de compreender as práticas de linguagem, a saber a interdiscursividade (BAKHTIN, 2011; MAINGUENEAU, 2005) e a prática discursiva (MAINGUENEAU, 1997), procurando vinculá-las à reflexão acerca dos impasses e desafios relativos à integração de refugiados em contextos sociais locais. Desse modo, interessa-nos tanto apresentar a maneira como pensamos o vínculo entre linguagem e mundo, quanto indicar questionamentos a serem adotados para investigar, nos documentos selecionados para esta análise, os sentidos construídos em torno das práticas que envolvem a mediação verbal.

Com efeito, o princípio que organiza nosso entendimento acerca da linguagem fundamentase na consideração de que todo enunciado, produzido em uma situação concreta de troca verbal, só pode ser compreendido em relação a outros enunciados, ainda que não haja marcas explícitas dessa vinculação na materialidade linguística desses enunciados (BAKHTIN, 2011, AUTHIER-REVUZ, 1990).

A esse respeito, o linguista russo M. Bakhtin (2011) propõe a noção de "compreensão responsiva ativa", em evidente contraposição aos modelos que concebiam a comunicação como emissão de uma mensagem que partiria de um ponto (o emissor) em direção a outro (o destinatário). Assentada em uma composição linearmente constituída, a mensagem emitida deveria ser conduzida ao destinatário e decodificada por ele. Além de postular a indesejável neutralidade do destinatário frente ao que se produz, esse modelo teria outro efeito negativo: o de supor que os textos conteriam mensagens a que se poderia ter acesso por procedimentos de segmentação de suas partes internas elementos linguísticos que conteriam índices (estáveis) de significação, cuja compreensão prescindiria de pistas fornecidas pelo contexto.

Ao lado desse plano "visível”, em que uma instância produz enunciados e outra os capta, Bakhtin (2011) propõe que se observe um outro nível - aquele em que a presença do outro se inscreve na própria materialidade dos enunciados. Desse modo, os enunciados que dirigimos a nossos interlocutores se instituem a partir de um duplo movimento: de um lado, pressupõem a existência de outros enunciados com os quais mantêm alguma relação (aliança, contraposição, etc) e, de outro, antecipam questionamentos, dúvidas, confirmações, entre outras posições atribuídas imaginariamente ao interlocutor.Retomando os termos do modelo clássico de comunicação, qualquer mensagem seria possível apenas se o falante for capaz de recuperar outros enunciados com os quais se mantém um diálogo. Segundo Bakhtin, os enunciados emergem como "réplicas" e se mantêm vinculados a elas, à semelhança do que ocorre nas conversas cotidianas.Com efeito, o diálogo cotidiano é alçado a modelo de interpretação de todas as trocas verbais, no que se tem denominado de dialogismo 
bakhtiniano. Recusa-se, nesse modelo, a ideia de que um enunciado pudesse ser compreendido apenas pelo acesso a elementos linguísticos segmentáveis, dotados de significação pretensamente estável. Estaríamos, então, no nível do que, em Análise do Discurso, se convencionou designar por “interdiscursividade” (PÊCHEUX, 1983, MAINGUENEAU, 2005).

Assumindo-se que os enunciados produzem sentido a partir das múltiplas relações que estabelecem com outros enunciados, em uma abordagem que se assenta portanto sobre um paradigma da alteridade, convencionou-se, por meio da contribuição de Authier-Revuz (1990), delimitar a inscrição da presença do outro em dois níveis enunciativos. Em um nível "visível”, haveria um modo de inscrição do outro na materialidade linguística por marcas como aspas, verbos de introdução da palavra de outrem (os verbos dicendi), expressões de reformulação, negação, entre outras. Esse nível comporia o que a autora denominou de heterogeneidade mostrada, sugerindo-se, pela presença das marcas mencionadas anteriormente, que a inscrição da palavra de outrem estaria delimitada naquela região da materialidade linguística. Tal dimensão "mostrada" caracteriza-se ainda por uma tensão fundamental com um segundo nível da presença do outro, que a autora denominou como constitutivo, postulando que, mesmo não estando mostrada, a presença da alteridade constitui todos os enunciados que compõem o inventário de uma comunidade linguística.

Em consonância com essa distribuição da alteridade em dois níveis, Maingueneau (2005) propõe uma correlação. Por um lado, um nível dialógico, isto é, um nível da interação constitutiva, decorrente do fato de que a polêmica não advém do exterior. Por outro, um nível polêmico, responsável pela heterogeneidade mostrada, no qual o adversário é interpelado diretamente, ocupando, então, lugar de destaque a citação, que dá visibilidade a "fragmentos localizáveis do Outro". A polêmica se instaura com o Outro, mas não com qualquer aspecto desse Outro: assiste-se a um duplo procedimento em toda e qualquer atividade de "tradução" - a filtragem e o comentário. Num primeiro momento, selecionam-se (filtram-se) os elementos que são importantes para reafirmar as regras positivas de um dado posicionamento discursivo (o que, em versões anteriores da $\mathrm{AD}$, convencionou-se chamar de formação discursiva). A seguir, o comentário, cujo objetivo é dirimir qualquer dúvida acerca da pertinência das regras reivindicadas por esse mesmo posicionamento.

Estaríamos aqui diante de uma questão que merece destaque, ao relacionar essa perspectiva teórica ao contexto de inserção local dos refugiados realizada, inclusive, por meio de práticas de linguagem. Longe de supor que falar uma língua pudesse se reduzir ao domínio de mecanismos combinatórios e armazenamento de itens lexicais, a discussão até aqui proposta ressalta a premissa de que produzir enunciados em uma língua supõe o compartilhamento de uma memória coletiva, cujo acesso é possibilitado de maneiras as mais diversas. Tal perspectiva demanda a produção de novas análises a respeito da inserção linguística de refugiados nas comunidades discursivas de acolhimento. 
A esse respeito, consideramos necessário repensar, em termos linguísticos, a distribuição binária "nativo"/"estrangeiro":

a designação 'estrangeiro' exibe uma distribuição de certo grupo de indivíduos em oposição a outro - o dos 'nativos' - não sem nos implicar na produção de uma certa zona indiscernível de neutralização da singularidade que constitui esse universo heterogêneo de experiências (ARANTES; DEUSDARÁ; BRENNER, 2016, p. 1201)

Desse modo, os estudos do discurso se interessam por interrogar essa dimensão do já-dito, desse universo discursivo com o qual os enunciados dialogam e no qual todos os falantes se inserem, ainda que involuntariamente. Como foi possível inferir na discussão anterior, a menção a textos anteriores não apenas explicita sua vinculação, mas também expressa em relação a eles um posicionamento, configurado por meio da polêmica. Destaque-se, a esse respeito, que uma dimensão pragmática subjacente aos textos convoca o quadro teórico da $\mathrm{AD}$ a formular sua concepção de base incorporando tal perspectiva.

Entre as iniciativas nessa direção, temos optado pela proposta de D. Maingueneau (1997), segundo a qual se sugere que a palavra "discurso" teria o inconveniente de fazer supor uma certa dissociação entre discurso e organização de mundo que o circundaria. A perspectiva adotada se caracteriza, fundamentalmente, pelo princípiosegundo o qual qualquer enunciado produz sentido em relação com outros enunciados, inscrevendo, nessa relação, um posicionamento.

Se os estudos inaugurais, no campo das análises do discurso, pareciam supor uma certa anterioridade das instituições frente aos textos produzidos por elas. A título de exemplo do que discutimos aqui, mencionaríamos o interesse pelo discurso político selecionado a partir do conjunto de pronunciamentos públicos manifestados por partidos políticos. No referido exemplo, teríamos a impressão de que os partidos seriam anteriores aos seus pronunciamentos públicos - resoluções, manifestos, proferimentos de seus porta-vozes autorizados, entre outras formas. Interessa-nos compreender, de modo mais alargado, a coprodução entre os discursos e as instituições, buscando redefinir cada um desses termos.

Em consonância com essa orientação, Maingueneau afirma que não há "antes, uma instituição, depois uma massa documental, enunciadores, ritos genéticos, uma enunciação, uma difusão e, enfim, um consumo, mas uma mesma rede que rege semanticamente essas diversas instâncias" (MAINGUENEAU, 2005, p. 142).

Como se observa nesse fragmento, a crítica a modelos lineares de comunicação, tal como proposta por M. Bakhtin, assume agora contornos amplos e possibilita repensar a vinculação entre linguagem e mundo. Nessa direção, a noção de discurso dá lugar à prática discursiva, como modo de 
ressaltar a reversibilidade entre as duas faces, social e textual, do discurso (MAINGUENEAU, 1997, p. 56):

A noção de prática discursiva integra, pois, estes dois elementos: por um lado, a formação discursiva, por outro, o que chamaremos de comunidade discursiva, isto é, o grupo ou a organização de grupos no interior dos quais são produzidos, gerados os textos que dependem da formação discursiva (MAINGUENEAU, 1997, p. 56)

Extrair a dimensão discursiva implicada nos textos supõe buscar reconhecer de que modo as alianças e contraposições construídas em sua superfície fazem ver a produção de grupos atuando em um espaço institucional delimitado. Procurando estabelecer uma vinculação com o tipo de questões que desejamos investigar no presente artigo, a leitura que propomos realizar dos documentos de referência não se limitaria a observar de que modo se fala sobre os refugiados, mas que qualidade de relações se supõem serem exercidas por e com eles, de que modo se apresentam os refugiados em ação e inter-relação na comunidade de integração, no quadro institucional que se desenha ao falar sobre eles, ao regular sua inserção no país de destino.

\section{UMA APROXIMAÇÃO AOS DOCUMENTOS EM ANÁLISE}

Neste item, apresentamos a justificativa para a escolha do material a ser submetido à análise, evidenciando que interesse nos move em direção a documentos que remetem a espaços institucionais distintos e recortam uma dimensão histórica determinada, a saber o Decreto Legislativo, de 1960, e o Plano de Ação do Brasil, de 2014.

Para uma melhor compreensão dos encaminhamentos de análise a serem indicados na sequência, parece-nos necessário contextualizar as condições de produção e emergência dos documentos em questão. Iniciaremos pelo texto do Decreto Legislativo n. 11, de 07 de julho de 1960, por meio do qual, apreendemos os sentidos subjacentes à instauração do instituto do refúgio no aparato legislativo brasileiro. Em consonância com esse aspecto, o referido Decreto apresenta, em sua Ementa, o seguinte texto: “Aprova a Convenção de 25 de julho de 1951, relativa ao Estatuto dos Refugiados, assinada pelo Brasil a 15 de julho de 19523". O texto da Ementa já fornece pistas produtivas dos ritos genéticos por meio dos quais sua enunciação se torna possível: uma Convenção, sua assinatura e a expedição de um Decreto.

Em relação ao Plano de Ação do Brasil, de 2014, considerando o referido texto particularmente interessante por possibilitar o recorte de um outro espaço institucional - aquele

\footnotetext{
${ }^{3}$ Disponível em: http://www2.camara.leg.br/legin/fed/decleg/1960-1969/decretolegislativo-11-7-julho-1960-349947publicacaooriginal-1-pl.html.
} 
viabilizado pela reunião da América latina e do Caribe, com vistas ao estabelecimento de, segundo o próprio documento, "Um Roteiro Comum para Fortalecer a Proteção e Promover Soluções Duradouras para as Pessoas Refugiadas, Deslocadas e Apátridas na América Latina e no Caribe em um Marco de Cooperação e Solidariedade"4. O Plano é também conhecido como Cartagena +30, em explícita menção à Declaração produzida em 1984, em Cartagena, e que possui como principal contribuição a expansão da definição de "refugiado", contida na Convenção de 1951. Embora se trate de documento não vinculante, a Declaração de Cartagena é reconhecida por 14 países, em suas legislações nacionais. O Plano de Ação do Brasil, portanto, se insere em uma complexa rede de enunciações que, além de reiterarem Declaração anterior, estabelecem pactos de ação regional, fornecendo uma leitura dos principais impasses e questões emergenciais e estratégicas, configurados pelos posicionamentos nos quais se inserem os governos e atores políticos da região.

Nessa direção, cabe explicitar as tensões que configuram a emergência desses documentos, buscando compreender de que modo a leitura desses materiais possibilita problematizar uma questão em especial: de que modo se constrói, no espaço institucional desenhado por eles, o exercício de práticas de linguagem pelos refugiados, em situação concreta de integração local.

Consideramos como bastante produtiva a problematização proposta por Agamben, segundo a qual a emergência da figura do refugiado coloca em questão a repartição binária cidadãoestrangeiro. Caracterizada tradicionalmente por "fundado temor de perseguição", a figura do refugiado se inscreve na ordem internacional denunciado as restrições às garantias fundamentais e o temor à suspensão da proteção humana, que se suporia ter papel fundante nas organizações dos Estados nacionais. Nessa direção, a fissura produzida na distribuição binária cidadão-estrangeiro se desdobra em uma interrogação sobre a própria ficção originária do Estados nacionais modernos:

Se os refugiados (cujo número nunca parou de crescer no nosso século [século XX], até incluir hoje uma porção não desprezível da humanidade) representam, no ordenamento do Estado-nação moderno, um elemento tão inquietante, é antes de tudo porque, rompendo a continuidade entre homem e cidadão, entre nascimento e nacionalidade, eles põem em crise a ficção originária da soberania moderna (AGAMBEN, 2007, p. 138).

Como correlato desse "desarranjo" provocado pela crescente intensificação dos fluxos de refugiados, Agamben (2015) destaca que se expõe uma fratura na dimensão humanitária da ordem constituída pelas Declarações de Direitos Humanos, na medida em que seu exercício se encontra estritamente vinculado ao interior dos Estados nacionais: "No sistema Estado-nação, os assim chamados direitos sagrados e inalienáveis do homem mostram-se desprovidos de toda tutela no

\footnotetext{
${ }^{4}$ Disponível em: http://www.acnur.org/fileadmin/Documentos/BDL/2014/9866.pdf
} 
próprio momento em que não é mais possível configurá-los como direitos dos cidadãos de um Estado" (AGAMBEN, 2015, p. 27).

Em análise de episódio recente, pessoas a bordo de um barco indonésio, em 2001, se encontram à deriva e alto-mar são resgatadas por embarcação norueguesa e impedidas de ingressar na Austrália. Diante da restrição à mobilidade evidenciada no evento, Reis (2004) afirma que episódios como esse confirmam "a constatação imediata de que o mundo é dividido em Estados, e Estados são associações que, entre outras características, possuem o monopólio de legitimidade da mobilidade" (REIS, 2004, p. 150).

Opinião semelhante é ratificada por Moulin (21012), contestando a seletividade implicada no processo contemporâneo. Vejamos o que a autora afirma a respeito dessa seletividade: “A economia política contemporânea permite e incentiva o deslocamento de produtos, informação e capital, mas procura restringir o deslocamento humano, por meio de estratégias de prevenção e controle intensivo de fronteiras" (MOULIN, 2012, p. 42).

$\mathrm{Na}$ discussão estabelecida, o tratamento conferido aos refugiados pelos Estados nacionais evidencia o acionamento de dispositivos de controle e disciplinamento diversos frente ao que tensiona justamente sua ficção fundante. Ao que parece, o interesse em regulamentar os condicionamentos do reconhecimento do estatuto de refugiados constituiria uma pista que pode ser analisada discursivamente, interrogando o que se silencia, quando o que se coloca em evidência é o desejo de regular fluxo de pessoas nas fronteiras nacionais.

Para Gomarasca (2017), o espaço moral de ação em relação aos refugiados supõe uma reflexão sobre as ações dirigidas a todos os grupos que se inseririam nessas que ele denomina de “fronteiras entre os que estão dentro e os que estão fora do espaço jurídico-político da cidadania":

Argumentar em favor de uma obrigação para com o refugiado ('dutytorefugee') não é tarefa fácil: implica uma reavaliação geral das práticas que utilizamos para determinar a nossa relação com os chamados outsiders, a começar por como estabelecemos as fronteiras entre os que estão dentro e os que estão fora do espaço jurídico-político da cidadania. (GOMARASCA, 2017, p. 15)

Retomando a densa reflexão acerca do histórico recente da delimitação da noção de "refugiado" e do papel do Alto Comissariado para Refugiados (ACNUR/ONU), Moulin destaca o predomínio de uma leitura que a concebe "como fonte de instabilidade e de insegurança por uma leitura securitizada dos deslocados" (MOULIN, 2012, p. 37). Em sua reflexão a autora demonstra que a diluição das classificações atribuídas à condição de refugiado é parte de uma espécie de "aparelho de captura", associado a um conjunto de sentidos e ações que sustentariam o projeto de 
evitar os deslocamentos e estabelecer iniciativas de manutenção dessas pessoas nas fronteiras dos países de origem:

As práticas vinculadas à securitização construíram o refugiado, na década de 1990, não só como um ser refugiado, mas como um vir-a-ser refugiado, pelos potenciais efeitos de sua extraterritorialidade, diluído em diversas classificações com pouca ou nenhuma validade pragmática, na medida em que tais classificações apenas asseguravam a atuação dentro dos países de origem, sendo difícil, na prática, distinguir entre as fronteiras e as discriminações artificiais dessas categorias (MOULIN, 2012, p. 37)

Ressaltamos especialmente a caracterização presente no referido estudo acerca da orientação que, segundo a autora, se poderia apreender da articulação entre o que são denominados como “instrumentos legais convencionais" e o que se passa a observar na atuação dos organismos internacionais, a partir dos anos 1990. De acordo com Moulin, os "instrumentos legais convencionais" se dirigiam ao tratamento conferido a pessoas que já se deslocaram. Tal orientação sustentava ações nos países de acolhimento. Essa orientação, segundo a autora, se desloca no desenvolvimento de estratégias variadas de contenção dos fluxos de mobilidade, configurando um tipo de ação preventiva:

É interessante notar que os instrumentos legais convencionais, ou seja, a Convenção de 1951 e o Protocolo de 1962, possuíam uma orientação post facto, direcionada para a assistência e proteção das pessoas que já cruzaram as fronteiras por motivos de perseguição, e que, por essa razão, poderiam ser categorizadas como refugiadas. Assim, a ação se concentrava, sobretudo, nos países de asilo e de reassentamento, onde poderia ser provida a atenção necessária aos contingentes já reconhecidos como refugiados. A estratégia preventiva, ao contrário, estava focada nos países de origem e na criação de mecanismos que, ao mesmo tempo, impediam violações massivas aos direitos das populações locais e, em certa medida, evitavam que referidas populações se tornassem refugiadas (MOULIN, 2012, p. 26)

Nos anos 1990, a autora observa indícios diversos que apontariam para uma maior atenção conferida às ações preventivas. De acordo com Moulin, um dos aspectos que motiva essa atenção reside no entendimento, por parte do ACNUR, de que a situação do refúgio já não poderia ser pensada como transitória e passível de resolução definitiva.

De fato, especialmente no que se refere às populações deslocadas, o objetivo era o de, sob o "véu da assistência humanitária", conter os fluxos e minimizar as "consequências não intencionais" dos conflitos sobre os países vizinhos e sobre a ordem do sistema internacional. Como ressaltou o Alto Comissário, em pronunciamento ao Conselho de Segurança, em maio de 2004, a maior preocupação do ACNUR e do Conselho de Segurança é com o "efeito sistêmico" que os referidos conflitos internos podem gerar (MOULIN, 2012, p. 24) 
Os impactos no processo de construção do refugiado, registrados pela autora, dão conta de uma diversidade de fatores que passamos a elencar:

i) difusão no emprego da categoria "refugiado", para além das motivações de perseguição estabelecidas pela Convenção de 1951, entre elas a menção a "refugiados ambientais", por exemplo, "reforçando a expansão do campo de atuação do ACNUR, ao mesmo tempo em que instigou debates sobre a necessidade de uma transformação do regime ou da criação de novas instâncias de regimentalização internacional" (MOULIN, 2012, p. 28);

ii) diversidade de categorias de "deslocados", provocando leituras restritivas do refúgio: "Note-se que, muitas vezes, foi a capacidade de encontrar uma solução durável para um determinado refugiado que garantiu a concessão ou não do estatuto, reforçando a leitura objetivista dos critérios que determinam quem pode ou não ser categorizado como um refugiado" (MOULIN, 2012, p. 28);

iii) as estratégias de prevenção produzindo políticas de contenção de refugiados em seus países de origem: "Note-se que, muitas vezes, foi a capacidade de encontrar uma solução durável para um determinado refugiado que garantiu a concessão ou não do estatuto, reforçando a leitura objetivista dos critérios que determinam quem pode ou não ser categorizado como um refugiado" (MOULIN, 2012, p. 28)

Parece-nos ainda necessário destacar de que modo essas engrenagens se atualizam no contexto brasileiro. Observa-se, entre nós, uma legislação que apresenta avanços significativos em relação a outras realidades nacionais. No entanto, tais avanços se desdobram em uma frágil rede de assistência social, agravada com reformas liberais recentes na legislação trabalhista e na contração de investimentos nos equipamentos sociais. Essa ambiguidade entre legislação e rede de assistência é registrada por Paiva, Dias e Moulin (2108):

Do ponto de vista normativo, comemoram-se os 20 anos da Lei 9.474/1997 que regula o estatuto do refugiado e delimita a política nacional de refúgio, bem como a aprovação de uma nova legislação migratória, a Lei 13.445/2017, orientada pela proteção aos direitos humanos da pessoa migrante e mais coadunada aos princípios constitucionais e internacionais sobre a temática. De outro, verifica-se o definhamento das estruturas burocráticas de proteção, particularmente da estrutura dos órgãos gestores dos processos migratórios - mal equipados, pouco coordenados e cronicamente sem equipe suficientemente robusta para dar conta das demandas do sistema - e a ausência de uma política para migrantes e refugiados que seja capaz de responder aos desafios da integração e à incorporação necessária desses grupos ao campo das políticas públicas (PAIVA; DIAS; MOULIN, 2018, p. 13-14) 
Sensível às orientações filosóficas e políticas subjacentes ao desenho institucional criticamente estabelecidos pelas referências adotadas aqui, Agamben parece promover a articulação entre fragilização das fronteiras nacionais e a condição de refugiado-em-nós:“Somente numa terra na qual os espaços dos Estados tiverem sido, desse modo, perfurados e topologicamente deformados e nos quais o cidadão terá sabido reconhecer o refugiado que ele mesmo é, é pensável hoje a sobrevivência política dos homens" (AGAMBEN, 2015, p. 33)

\section{O APAGAMENTO DA DIMENSÃO LINGUÍSTICA EM DOCUMENTOS DE REFERÊNCIA}

Neste item, apresentamos as análises empreendidas nos documentos indicados anteriormente, procedendo-se, inicialmente, a uma caracterização dos gêneros nos quais se inscrevem e buscando, na sequência, marcas que possibilitem restituir as polêmicas que lhes dão sustentação. Conforme descrito anteriormente, a análise das práticas discursivas requer a delimitação de marcas linguísticas que permitam recuperar, na materialidade textual, índices que remetam à reversibilidade das faces textual e social dos discursos.

Nessa direção, a noção de gêneros do discurso é categoria central para caracterizar essa entrada, por possibilitar observar o funcionamento das formas instituídas de enunciação. A definição original dessa noção remete à contribuição de Bakhtin, assumindo os gêneros do discurso como "tipos relativamente estáveis de enunciados" (BAKHTIN, 2011), compostos por estilo, temática e construção composicional. Como se observa, essa definição original teria o mérito de vincular indissoluvelmente o que se diz e o modo como se diz, assumindo essa articulação não como resultante de escolhas individuais dos falantes, mas como efeitos da produção sócio-histórica de linguagem. Para Bakhtin, cada esfera da atividade humana comportaria certos gêneros do discurso.

Nas análises propostas, o acesso ao Decreto Legislativo, aprovado pelo Senado Federal, e ao Plano de Ação, composto por atividade diplomática, mediada por consultas sub-regionais ${ }^{5}$, nos insere em uma esfera da atividade estatal que se realiza pela articulação entre esferas governamentais, organizadas regionalmente, e esferas legislativas, reguladas internamente em cada um dos Estados. Nesse nível, observamos a produção de um texto que emerge da articulação em uma cadeia complexa de enunciações e, ao mesmo tempo, teria como propósito a produção de uma enunciação que se supõe consensual, "pacificando" as tensões locais, regionais e globais. Trata-se de um elemento que

\footnotetext{
${ }^{5}$ De acordo com o Plano de Ação do Brasil, foram realizadas quarto consultas sub-regionais: "quatro consultas subregionais realizadas durante 2014, em Buenos Aires (18 e 19 de Março) para os países do Mercado Comum do Sul (MERCOSUL), em Quito (9 e 10 de Junho) para os países andinos, em Manágua (10 e 11 de Julho) para os países da Mesoamérica, e em Grande Caimã (10 e 11 de Setembro) para a subregião do Caribe”.
} 
caracteriza um interesse especial pelo referido material, ao mesmo tempo em que oferece algumas dificuldades, justamente por se dever se caracterizar pelo apagamento das polêmicas que se encontram na base de qualquer enunciação.

Nesse sentido, a opção pela noção de gêneros do discurso como noção operatória possibilita apreender os diferentes aspectos da instituição: (i) finalidade reconhecida, referindo-se ao projeto de dizer; (ii) estatuto dos coenunciadores, ressaltando-se a dinâmica distribuídas entre os parceiros da interação verbal; (iii) espaço-tempo, observando-se a instauração de coordenadas de referência pela própria enunciação; (iv) organização textual, compreendendo a extensão do texto, a articulação entre as partes, os modos de coesão intradiscursiva; (v) midium, (MAINGUENEAU, 2001).

\section{1 "Decreto Legislativo" (que contém) "Convenção Internacional"}

Neste item, apresentamos as análises empreendidas do Decreto Legislativo, explicitando as pistas de seu funcionamento institucional. Nas análises preliminares do Decreto Legislativo, consideramos relevante buscar compreender a previsão legal para o referido documento, de modo que se possa acessar, nos textos que prescrevem sua enunciação, pistas do funcionamento do gênero.

Reconhecendo o papel do texto constitucional na prescrição das atividades privativas de cada um dos Poderes, identificamos, nele, a previsão pra a expedição de Decretos Legislativos pelo Senado Federal. Trata-se, como se pode observar, de prática discursiva fortemente instituída, prevista no Art. 49:

Regula matérias de competência exclusiva do Congresso, tais como: ratificar atos internacionais, sustar atos normativos do presidente da República, julgar anualmente as contas prestadas pelo chefe do governo, autorizar o presidente da República e o vice-presidente a se ausentarem do país por mais de 15 dias, apreciar a concessão de emissoras de rádio e televisão, autorizar em terras indígenas a exploração e o aproveitamento de recursos hídricos e a pesquisa e lavra de recursos minerais. ${ }^{6}$

Desse modo, no que tange à pista das finalidades instituídas para esse gênero do discurso parlamentar estão atos que se fundam nos projetos de ratificar, sustar, julgar, autorizar, apreciar, autorizar, demonstrando, em diversos casos, a dinâmica de relação entre os poderes, inscrita nessas finalidades. Para o caso em análise, trata-se especificamente de "ratificar atos internacionais", explicitando um primeiro nível dos ritos genéticos implicados no Decreto. Em "ratificar atos internacionais", o traço semântico que prevalece em "ratificar" é o de "confirmação" [de ato internacional], nesse caso, uma Convenção da ONU. Confirmação que se realiza pela reprodução de

\footnotetext{
${ }^{6}$ Disponível em: https://www12.senado.leg.br/noticias/glossario-legislativo/decreto-legislativo
} 
partes integrais, pela menção a exclusões do texto original e pela versão em língua nacional desse original.

Na Imagem 1, observam-se indícios do que indicamos anteriormente:

\title{
Imagem 1 - Decreto Legislativo n. 11/1960 - trecho inicial $^{7}$ \\ DECRETO LEGISLATIVO Nº11, DE 1960
}

\begin{abstract}
Aprova a Convenção de 25 de julho de 1951, relativa ao Estatuto dos Refugiados, assinada pelo Brasil a 15 de julho de 1952.

Art. $1^{\circ}$ É aprovada a Convenção de 25 de julho de 1851, relativa ao Estatuto dos Refugiados, assinada pelo Brasil, a 15 de julho de 1952, com exclusão dos artigos 15 e 17.

Art. $2^{\circ}$ Êste decreto legislativo entrará em vigor na data de sua publicação, revogadas as disposições em contrário.

SENADO FEDERAL, em 7 de julho de 1960.

SEnador FILINTO MÜLLER

VICE-PRESIDENTE, no exercício da PRESIDÊNCIA

CONVENÇÃo RELATIVA AO ESTATUTO DOS REFUGIADOS

Adotada em 28 de julho de 1951 pela Conferência das Nações Unidas dePlenipotenciários sobre o Estatuto dos Refugiados e Apátridas, convocada pela Resolução 429 (V) da Assembléia Geral das Nações Unidas, de 14 de dezembro de 1950.

As Altas Partes Contratantes,

Considerando que a Carta das Nações Unidas e a Declaração Universal dos Direitos Humanos, aprovada em 10 de dezembro de 1948 pela Assembléia Geral, afirmaram o princípio de que os seres humanos, sem distinção, devem gozar dos direitos do homem e das liberdades fundamentais,

Considerando que a Organização das Nações Unidas tem repetidamente manifestado sua profunda preocupação pelos refugiados e que tem se esforçado por assegurar-lhes o exercício mais amblo nossível dos direitos do homem e das liberdades fundamentais.
\end{abstract}

O Decerto possui, além da Ementa, dois Artigos. No primeiro, anuncia-se sua vinculação com a Convenção e com o momento da assinatura do Brasil - inserindo-se em uma sequência temporal encadeada -, bem como indica-se a "exclusão dos artigos 15 e 17". No segundo, tem-se o enunciado que remete a uma ritualística das práticas legislativa: "Êste decreto legislativo entrará em vigor na data de sua publicação, revogadas as disposições em contrário" - instaurando o presente contínuo, relativo ao que passa a ocorrer, a partir de sua publicação em Diário Oficial da União. Após a assinatura, inicia-se o texto ratificado da "CONVENÇÃO RELATIVA AO ESTATUTO DOS REFUGIADOS", que foi "Adotada em 28 de julho de 1951 pela Conferência das Nações Unidas dePlenipotenciários sobre o Estatuto dos Refugiados e Apátridas, convocada pela Resolução 429 (V) da Assembléia Geral das Nações Unidas, de 14 de dezembro de 1950”.

Como se pode observar, estamos diante de um gênero Decreto Legislativo, que se institui (ratificando) outro gênero, uma Convenção Internacional. Trata-se de um procedimento denominado discurso relatado (MAINGUENEAU, 2001). Nesse caso, não da citação de partes, ou pequenos trechos de um texto por outro, mas da citação (quase) integral, de um texto por outro. O efeito de sentido da citação de um gênero por outro parece inscrever-se em dois níveis: i) assiste-se ao diálogo estabelecido entre "Estados Contratantes", assumindo compromissos; ii) tem-se acesso a tensões entre a "forma de lei” X indícios da Assembleia Geral (contrato).

\footnotetext{
${ }^{7}$ Disponível em: http://www2.camara.leg.br/legin/fed/decleg/1960-1969/decretolegislativo-11-7-julho-1960-349947publicacaooriginal-1-pl.html
} 
Entre os ritos genéticos presumidos observa-se o encadeamento de Convenções a respeito dos deslocamentos forçados: Convenção Relativa aos Apátridas (1954); Convenção de Prevenção da Formação de Apátridas (1961); Protocolo de Refugiados (1967) - ampliação do conceito de refugiados para outros tipos de situação.

Outra pista proporcionada pelo dispositivo dos gêneros do discurso reside na organização textual. Observando previamente a dinâmica de enunciação por capítulos, com um certo perfil do emprego do código de linguagem e recursos formais, optamos pela apresentação dos Capítulos em correlação com os Artigos, de modo que se possa ter acesso ao tipo de temática de interesse, na maior parte do texto:

Quadro 1 - Correlação entre Capítulos e Artigos do Decreto-legislativo

\begin{tabular}{|c|c|}
\hline Capítulo & Artigos \\
\hline I Disposições Gerais & $\begin{array}{l}1^{\circ} \text { Definição do termo "refugiado" } \\
2^{\circ} \text { Obrigações gerais } \\
3^{\circ} \text { Não-discriminação } \\
4^{\circ} \text { Religião } \\
5^{\circ} \text { [sem título] } \\
6^{\circ} \text { A expressão "nas mesmas circunstâncias" } \\
7 \text { o Dispensa de reciprocidade } \\
8^{\circ} \text { Dispensa de medidas excepcionais } \\
9^{\circ} \text { Medidas provisórias } \\
10^{\circ} \text { Continuidade de residência } \\
11^{\circ} \text { Marinheiros refugiados }\end{array}$ \\
\hline II Situação Jurídica & $\begin{array}{l}12^{\circ} \text { Estatuto pessoal } \\
13^{\circ} \text { Propriedade móvel e imóvel } \\
14^{\circ} \text { Propriedade intelectual e industrial } \\
15^{\circ} \text { Direitos de associação } \\
16^{\circ} \text { Direito de propugna } r \text { em juízo }\end{array}$ \\
\hline III Empregos Remunerados & $\begin{array}{l}17^{\circ} \text { Profissões assalariadas } \\
18^{\circ} \text { Profissões não assalariadas } \\
19^{\circ} \text { Profissões liberais }\end{array}$ \\
\hline IV Bem-Estar & $\begin{array}{l}20^{\circ} \text { Racionamento } \\
21^{\circ} \text { Alojamento } \\
22^{\circ} \text { Educação pública } \\
23^{\circ} \text { Assistência pública } \\
24^{\circ} \text { Legislação do trabalho e previdência social }\end{array}$ \\
\hline V Medidas Administrativas & $\begin{array}{l}25^{\circ} \text { Assistência administrativa } \\
26^{\circ} \text { Liberdade de movimento } \\
27^{\circ} \text { Papéis de identidade } \\
28^{\circ} \text { Documentos de viagem } \\
29^{\circ} \text { Despesas fiscais } \\
30^{\circ} \text { Transferência de bens } \\
31^{\circ} \text { Refugiados em situação irregular no país de refúgio } \\
32^{\circ} \text { Expulsão } \\
33^{\circ} \text { Proibição de expulsão o u de rechaço } \\
34^{\circ} \text { Naturalização }\end{array}$ \\
\hline $\begin{array}{l}\text { VI Disposições Executórias e } \\
\text { Transitórias }\end{array}$ & $\begin{array}{l}35^{\circ} \text { Cooperação das autoridades nacionais com as Nações Unidas } \\
36^{\circ} \text { Informações sobre as leis e regulamentos nacionais } \\
37^{\circ} \text { Relações com as convenções anteriores }\end{array}$ \\
\hline
\end{tabular}




\begin{tabular}{|l|l|}
\hline VII Cláusulas Finais & $38^{\circ}$ Solução dos dissídios \\
& $39^{\circ}$ Assinatura, ratificação e adesão \\
& $40^{\circ}$ Cláusula de aplicação territorial \\
& $41^{\circ}$ Cláusula federal \\
& $42^{\circ}$ Reservas \\
& $43^{\circ}$ Entrada em vigor \\
& $44^{\circ}$ Denúncia \\
& $45^{\circ}$ Revisão \\
& $46^{\circ}$ Notificações pelo Secretário-Geral das Nações Unidas \\
\hline
\end{tabular}

No Art. $2^{\circ}$, inscreve-se um marco temporal, remetendo a "acontecimentos ocorridos antes de $1^{\circ}$ de janeiro de 1951". Já no inciso B.1) b, inscreve-se uma curiosa coordenada de espaço "na Europa ou alhures":

“2) Que, em consequência dos acontecimentos ocorridos antes de $1^{\circ}$ de janeiro de 1951 e temendo ser perseguida por motivos de raça, religião, nacionalidade, grupo social ou opiniões políticas, encontra-se fora do país de sua nacionalidade e que não pode ou, em virtude desse temor, não quer valer-se da proteção desse país, ou que, se não tem nacionalidade encontra-se fora do país no qual tinha sua residência habitual em consequência de tais acontecimentos, não pode ou, devido ao referido temor, não quer voltar a ele'

B. 1) Para os fins da presente Convenção, as palavras 'acontecimentos ocorridos antes de $1^{\circ}$ de janeiro de $1951^{\prime}$, do art. $1^{\circ}$, seção A, poderão ser compreendidos no sentido de

a) 'acontecimentos ocorridos antes de $1^{\circ}$ de janeiro de 1951 na Europa'; ou

b) 'acontecimentos ocorridos antes de $1^{\circ}$ de janeiro de 1951 na Europa ou alhures"

As marcas de espaço e tempo registram um desenho importante do instituto do refúgio: tratase de um mecanismo originariamente europeu e temporalmente situado.

Essa será a ênfase proposta pela Convenção: arbitrar a respeito da definição e de medidas administrativas e jurídicas relativas a esse instituto. Muito pouco se fala sobre o "Bem-estar" - modo como se designava o conjunto de aspectos no campo da integração. E, nesse sentido, observamos um apagamento da diversidade linguística e cultural. Nem mesmo quando se fala em acesso à Educação pública, há qualquer menção à língua:

\footnotetext{
Artigo 22

Educação pública

1. Os Estados Contratantes darão aos refugiados o mesmo tratamento que é dado aos nacionais no que concerne ao ensino primário.

2. Os Estados Contratantes darão aos refugiados um tratamento tão favorável quanto possível, e em todo caso não menos favorável do que aquele que é dado aos estrangeiros em geral, nas mesmas circunstâncias, no que concerne aos graus de ensino superiores ao primário, em particular no que diz respeito ao acesso aos estudos, ao reconhecimento de certificados de estudos, de diplomas e títulos universitários estrangeiros, à isenção de emolumentos alfandegários e taxas e à concessão de bolsas de estudos.
}

Nessa dinâmica de apagamento da diversidade linguística, chama especial atenção o modo como se constrói sentido acerca do "refugiado" em associação ao "estrangeiro". Essa associação é 
introduzida por meio das expressões "tão favorável quanto possível" e "não menos favorável do que". Embora não haja menção explícita à figura do "cidadão", o emprego dessas expressões instaura duas ordens de pressuposição: i) o tratamento a refugiados é possivelmente desfavorável em relação ao estrangeiro; ii) nem sempre garantir essa condição (menos) (des)favorável é possível.

\subsection{Plano de Ação do Brasil}

Neste item, apresentamos nossas análises acerca do Plano de Ação do Brasil. Trata-se de um Plano de Ação vinculado à “Declaração do Brasil”, que é considerado, pelo próprio documento, “um Marco de Cooperação e Solidariedade Regional para Fortalecer a Proteção Internacional das Pessoas Refugiadas, Deslocadas e Apátridas na América Latina e no Caribe”. Trata-se, como já o dissemos, de documento produzido a partir de quatro consultas regionais e lançado em Brasília, em 2014.

Em seus ritos genéticos, inscrevem-se tanto as consultas, reuniões, intercâmbios de informações e debates no contexto de seu lançamento, bem como sua vinculação com as comemorações da Declaração de Cartagena: "Reunidos na cidade de Brasília para comemorar o trigésimo aniversário da Declaração de Cartagena sobre Refugiados de 1984”.

Em relação à finalidade reconhecida, identificamos um gênero menos instituído do que o Decreto Legislativo, sem que isso represente uma organização interna mais distensa. Ao contrário, sua organização se realização por meio de um modo de coesão interna frequentemente reiterado.

A título de exemplificação, apresentamos a seguir dois fragmentos em que são explicitadas ações a serem adotadas pelos países signatários:

\footnotetext{
"Promover a adoção de políticas públicas integrais e sua inclusão nos planos nacionais de desenvolvimento que atendam às necessidades das pessoas refugiadas, deslocadas ou apátridas, contando com sua participação e a das comunidades de acolhida, e multiplicar esforços para garantir o gozo dos direitos econômicos, sociais e culturais, incluindo os laborais, levando em consideração as necessidades diferenciadas dos grupos e populações em situação de vulnerabilidade, a fim de promover sua integração local" (p. 5)

"Propiciar políticas de hospitalidade e não discriminação para fortalecer a integração local através da promoção do respeito à diversidade e à interculturalidade, ressaltando o aporte positivo das pessoas refugiadas, deslocadas e apátridas para as comunidades de acolhida." (p. 5)
}

Como se pode observar, os verbos, no infinitivo, encontram-se em destaque ("promover", “multiplicar [esforços]", "propiciar"), ressaltando-se o tipo de ação a que se faz menção. Nos complementos verbais, observa-se o emprego reiterados da flexão nominal de plural “a adoção de políticas públicas integrais", "esforçoș”, antecipando variações regionais nas modalidades de ações empreendidas e, ao mesmo tempo, explicitando o foco maior no compromisso do que na efetividade das ações. 
$\mathrm{Na}$ sequência, analisamos a organização textual, observando os Capítulos e suas partes internas:

Quadro 2 - Correlação entre Capítulos e Subdivisões internas do Plano de Ação do Brasil

\begin{tabular}{|c|c|}
\hline Capítulos & Subdivisões internas \\
\hline \multicolumn{2}{|l|}{ PREÂMBULO } \\
\hline \multicolumn{2}{|l|}{$\begin{array}{l}\text { CAPÍTULO PRIMEIRO } \\
\text { A Situação das Pessoas Refugiadas, Deslocadas e } \\
\text { Apátridas na América Latina e no Caribe }\end{array}$} \\
\hline \multirow{2}{*}{$\begin{array}{l}\text { CAPÍTULO SEGUNDO } \\
\text { A Proteção Internacional das Pessoas Refugiadas e } \\
\text { Solicitantes de Asilo }\end{array}$} & Programa "Asilo de Qualidade" \\
\hline & Programa "Fronteiras Solidárias e Seguras" \\
\hline \multirow{4}{*}{$\begin{array}{l}\text { CAPÍTULO TERCEIRO } \\
\text { Soluções Integrais, Complementares e Sustentáveis }\end{array}$} & Programa "Repatriação Voluntária" \\
\hline & Programa "Integração Local" \\
\hline & Programa "Reassentamento Solidário" \\
\hline & Programa "Mobilidade Laboral" \\
\hline \multirow{3}{*}{$\begin{array}{l}\text { CAPÍTULO QUARTO } \\
\text { Solidariedade com o Triângulo Norte da América } \\
\text { Central na Busca e Implementação de Soluções } \\
\text { Duradouras }\end{array}$} & $\begin{array}{l}\text { Programa "Observatório de Direitos Humanos } \\
\text { para o Deslocamento" }\end{array}$ \\
\hline & Programa "Prevenção" \\
\hline & Programa "Trânsito Digno e Seguro" \\
\hline $\begin{array}{l}\text { CAPÍTULO QUINTO } \\
\text { Solidariedade Regional com o Caribe para uma } \\
\text { Resposta Integral de Proteção Internacional e } \\
\text { Soluções Duradouras }\end{array}$ & $\begin{array}{l}\text { Programa "Solidariedade } \\
\text { Caribe" }\end{array}$ \\
\hline $\begin{array}{l}\text { CAPÍTULO SEXTO } \\
\text { Apatridia }\end{array}$ & Programa "Erradicação da Apatridia" \\
\hline $\begin{array}{l}\text { CAPÍTULO SÉTIMO } \\
\text { Cooperação Regional }\end{array}$ & [Não se aplica] \\
\hline $\begin{array}{l}\text { CAPÍTULO OITAVO } \\
\text { Implementação e Acompanhamento }\end{array}$ & [Não se aplica] \\
\hline
\end{tabular}

Observando a organização interna acima explicitada, percebe-se que a tematização das políticas e práticas de integração, foco central da discussão proposta neste artigo, se realiza especialmente no Capítulo Três intitulado "Soluções Integrais, Complementares e Sustentáveis", subdividido em internamente em quatro Programas, a saber: i) "Programa 'Repatriação Voluntária"; ii) "Programa 'Integração Local"; iii)"Programa "Reassentamento Solidário"; iv) "Programa 'Mobilidade Laboral".

A partir dessa opção, realizamos nova leitura dos referidos programas, observam que, dos quatro programas, apenas dois se destinam a debater a temática de interesse: "Programa 'Integração Local" e "Programa "Mobilidade Laboral". Uma nova análise dos trechos relativos aos dois Programas demonstra que apenas em um deles se observa a menção ao "linguístico". 
Desse modo, já se pode observar uma espécie de contração das práticas de inscrição local dos refugiados, mantendo-se a centralidade das ações estatais e da regulação das fronteiras, em detrimento as experiências concretas.

\section{Programa "Mobilidade laboral"}

“e) Fomentar programas de capacitação profissional e vocacional, e de adaptação cultural, social e lingüística.” (p. 14)

Nesse item, articulam-se sentidos relativos à "captação" e à "adaptação", inserindo a dimensão linguística no contexto da "mobilidade laboral", cuja efetividade requer certo nível de "adaptação". Como se vê, ainda que haja alguma menção ao linguístico, essa menção se realiza pressupondo uma avaliação negativa: o traço semântico preponderante em "adaptação" sugere a existência de algo prévio que demandaria ajustes a uma ordem dada. A diversidade linguística aqui é assumida como algo que poderia impedir ou dificultar a "mobilidade laboral”. Por extensão, não se imagina a possibilidade de a "mobilidade laboral" se dar justamente por meio de uma ampliação do repertório linguístico das populações em contato. Acresce-se a isso a ideia de que as línguas poderiam ser dimensões das quais os falantes poderiam se afastar com facilidade, atualizando um posicionamento instrumental a respeito das línguas e um apagamento de qualquer debate acerca dos direitos linguísticos dos falantes.

\section{CONSIDERAÇõES FINAIS}

No presente artigo, propomos discussão a respeito das práticas e políticas de integração dos refugiados, por meio de análise dos documentos de referência. Nessas análises, pretendíamos observar a construção de sentidos sobre o refugiado como falante de uma língua estrangeira, investigando de que modo esses sentidos seriam construídos nesses documentos de referência.

Em alguma medida, nosso desejo se fundava no propósito de avaliar a produtividade da inserção do linguista na rede de proteção e acolhimento a refugiados, afirmando a pertinência do diálogo entre a Linguística e outras áreas do conhecimento para lidar com questões concretas e urgentes. Experimentamos, desse modo, um diálogo com as reflexões já consolidadas na pesquisa acadêmica sobre a temática, em especial sobre a construção do instituto do refúgio no último período e sugerimos uma entrada de análise, por meio da noção de prática discursiva (MAINGUENEAU, 1997).

Com o intuito de destacar uma possível contribuição dos estudos linguísticos às práticas de acolhimento a refugiados e com base em nosso diálogo com o campo de estudos do refúgio, 
formulamos a hipótese de que o lugar conferido às práticas de linguagem encontra-se secundarizado frente ao interesse por regulamentar administrativa e juridicamente a condição de refugiado. Ao final das análises, para além da secundarização inicialmente imaginada, constatamos um apagamento da dimensão linguística, bem como da afirmação de sua diversidade no campo dos direitos linguísticos. Silenciam-se, desse modo, as tensões, impasses, desafios experimentados pelos refugiados nos circuitos comunitários nos quais se inscreve: mobilidade urbana, acesso a serviços de educação e saúde, acesso aos bens culturais disponíveis na cidade. Toda essa dimensão que é destacada e problematizada por eles não encontra qualquer representação no documento investigado. Desse modo, compreendemos que o necessário destaque conferido ao processo administrativo e jurídico de reconhecimento da condição de refugiado não pode silenciar os impasses linguísticos vivenciados no cotidiano de uma comunidade na qual circulam estereótipos e mitos de um pretenso monolinguismo - intensamente descontruído pelas investigações no campo dos estudos da linguagem. Com efeito, identificamos uma clara contribuição dos estudos linguísticos para o campo de estudos do refúgio, contribuindo para ressaltar que, desde o processo de solicitação de refúgio até seu reconhecimento, o que temos são pessoas falantes de línguas estrangeiras, vivenciando conflitos diversos no contexto de integração, incluindo aqueles relativos à não garantia do pleno acesso à língua da comunidade de recepção.

O silêncio diante de uma necessária política linguística nos documentos em análise fornece pistas que consideramos bastante instigantes para a discussão a respeito dos desafios implicados nas políticas e nas práticas de acolhimento a refugiados. A despeito do que possa estar previsto em legislação correlata acerca dos direitos linguísticos das populações no Brasil, a ausência de qualquer regulação nesse sentido parece contribuir com a construção social do refugiado em termos jurídicopolicial e econômico-utilitário, apagando-se a dimensão política dos direitos e de política de cultura.

Como última palavra, parece-nos que essas reflexões, não pelo que apreendem no universo do efetivamente dito nas documentos de referência, mas especialmente tipo apreensões de uma espécie de interdição sobre a língua e, por consequência, os direitos linguísticos dos falantes, sugerem o diálogo com perspectiva renovadas no campos das políticas linguísticas, recusando, como já o dissemos anteriormente, a separação entre agentes estatais e os pesquisadores que atuam na micropolítica, tomando decisões que ainda não ganharam corpo nos documentos e referência:

Assim, rejeitando toda forma de divórcio entre agentes estatais que decidem e executam uma ação incisiva de políticas estatais e cientistas que não fariam senão falar a respeito, o que não ratificamos, na realidade, é o lugar de saber-poder que se pretende conferir à ciência, o qual, sustentado pela lógica dos especialismos, funciona muito convenientemente como álibi para o seu descomprometimento frente às escolhas éticas que implicarão a construção de uma dada qualidade de social. A 
divisão entre aqueles que sabem e os que não sabem é um dos pilares do capitalismo para a produção de subjetividades controladoras e subjetividades tuteladas (DEUSDARÁ; ARANTES; ROCHA, 2017, p. 283)

Trata-se de uma articulação necessária com a perspectiva que vem se afirmando na glotopolítica, que "procura identificar formas de luta contra a dominação linguística, partindo de um claro engajamento democrático junto com quem nada tem, nem sequer a Língua" (LAGARES, 2018, p. 41).

\section{REFERÊNCIAS}

AGAMBEN, G. Meios sem fim: notas sobre a política. Tradução de Davi Pessoa. Belo Horizonte: Autêntica, 2015.

AGAMBEN, G. Homo sacer: o poder soberano e a vida nua I. Trad. de Henrique Burigo. Belo Horizonte: Ed. da UFMG, 2007.

ARANTES, P.C.C.; DEUSDARÁ, B. Português para Refugiados: Aliando Pragmática e Discurso em resposta a uma demanda concreta. Revista Letrônica, v. 8, n. 1, 2015. Disponível em: http://revistaseletronicas.pucrs.br/ojs/index.php/letronica/article/view/19621. Acesso em: 01 jul. 2018.

ARANTES, P. C. C.; DEUSDARÁ, B.; BRENNER, A. K. Língua e alteridade na acolhida a refugiados: por uma micropolítica da linguagem. Fórum Linguístico, Florianópolis, v.13, n.2, p. 1196-1207, abr./jun. 2016. Disponível em: https://periodicos.ufsc.br/index.php/forum/article/view/1984-8412.2016v13n2p1196/32092. Acesso em: 01 jul. 2018.

AUTHIER-REVUZ, J. Heterogeneidade(s) enunciativa(s). Cadernos de Estudos Linguísticos, v. 19, jul./dez., 1990.

BAKHTIN, M. M. Estética da Criação Verbal. Trad. do russo de Paulo Bezerra. 6. ed. São Paulo: Martins Fontes, 2011.

BAKHTIN, M. M. Marxismo e Filosofia da Linguagem. Trad. de Michel Lahud e Yara F. Vieira. São Paulo: Hucitec, 2004.

BRASIL. Lei nº 9.474, 22 de julho de 2007. Disponível em: Acesso em: 18 dez. 2014.

CÁRITAS BRASILEIRA. Estatuto da Cáritas Brasileira. Estatuto registrado no Cartório de Registro Civil das Pessoas Jurídicas Rio de Janeiro/RJ, sob o n ${ }^{\circ} 15.611$, Livro A' no 7 , em 05/08/1966.

DEUSDARÁ, B.; ARANTES, P. C. C.; ROCHA, D. Cruzando fronteiras: a promoção de direitos com refugiados nas práticas de ensino de línguas. Gragoatá, Niterói, v. 22, n. 42, p. 268-288, jan./abr. 2017. Disponível em: http://www.gragoata.uff.br/index.php/gragoata/article/view/885/642. Acesso em: 06 jul. 2018.

GOMARASCA, P. Direito de excluir ou dever de acolher? A migração forçada como questão ética. REMHU, Rev. Interdiscip. Mobil. Hum., Brasília, v. 25, p. 11-24, n. 50, ago. 2017.

LAGARES, X. C. Que política linguística? Desafios glopolíticos contemporâneos. São Paulo: Parábola, 2018. 
MAINGUENEAU, D. Novas Tendências em Análise do Discurso. Tradução de FredaIndursky. Campinas: Pontes; Ed. da Unicamp, 1997.

MAINGUENEAU, D. Gênese dos discursos. Tradução de Sírio Possenti. Curitiba: Criar, 2005.

MAINGUENEAU, D. Análise de Textos de Comunicação. Tradução de Cecília Souza-e-Silva e Décio Rocha. São Paulo: Cortez, 2001.

MOULIN, C. A construção do refugiado no pós-Guerra Fria: dilemas, complexidades e o papel do ACNUR. Carta Internacional. v. 7, n. 2, p. 23-49, 2012.

PAIVA, A. R. de.; DIAS, A. C. S.; MOULIN, C. Migrações e refúgio: travessias interdisciplinares, desafios globais.O Social em Questão, v. 21, n. 41, p. 9-22, maio/ago. 2018.

RAMOS, E. M. S. Los imperativos culturales como garantía de losderechosdelinmigrante. Revista de laFacultad de Derecho, n· 41, p. 287-311, jul./dic. 2016.

REIS, R. R. Soberania, Direitos Humanos e Migrações Internacionais. Revista Brasileira de Ciências Sociais, v. 19, n. 55, p. 149-164, 2004. 